\begin{tabular}{|ccc}
\hline Sournals & $\begin{array}{c}\text { INTERNATIONAL JOURNAL OF } \\
\text { ORGANIZATIONAL LEADERSHIP }\end{array}$ & $\begin{array}{c}\text { INDUSTRIAL } \\
\text { MANAGEMENT } \\
\text { INSTITUTE }\end{array}$ \\
\hline \hline
\end{tabular}

\title{
Review of practical implications in ethical leadership studies
}

\author{
Özlem Ayaz Arda ${ }^{*}$, Tuğçe Aslan ${ }^{2}$, Lütfihak Alpkan ${ }^{3}$ \\ ${ }^{1}$ Postdoctoral Research Fellow in Faculty of Management, Istanbul Technical University Macka, Istanbul, \\ 34349, Turkey \\ ${ }^{2}$ Doctoral Candidate, PhD Program in Management and Organization, Graduate School of Social Sciences, \\ Bahcesehir University, Besiktas, Istanbul, 34353, Turkey \\ ${ }^{3}$ Head of Management Department, Istanbul Technical University, Macka, Istanbul, 34349, Turkey
}

\section{Keywords: \\ Ethical Leadership, Ethical Behavior, Practical Implications}

\section{Received}

06 April 2017

Received in revised form 29 June 2017

Accepted

01 July 2017

Correspondence: arda16@itu.edu.tr

\section{Abstract}

Unfavorable effects of unethical treatments and transactions have been under serious consideration both academically and professionally. The question of how to improve ethical sensitivity in decision-making has begun to attract more and more attention. Thus, professionals have tried to consider developing ethical leadership in their organizations substantially, while scholars have begun to study its possible antecedents and outcomes. Emphasizing practical implications of ethical leadership, this study aims to analyze leaders' behaviors based on their ethical decisions, their adoption level of ethical leadership, the degree that they have integrated ethics into their management styles, and their relations with the followers and subordinates. In this respect, authors investigate ethical leadership studies in top organizational behavior journals and categorize these studies according to their implications. The practical implications of these studies, which are related to ethical leadership, are examined in detail to excerpt a common idea about this specific style of leadership and its consequences in various industries.

CAIMI Journals

Recent developments in both external market conditions and internal organizational dynamics showed the importance of business ethics and emphasized the detrimental effects of unethical treatments and transactions. On the one hand, deliberately unethical leadership behaviors are still in common use in all over the world to get short-term material gain regardless of whatever pain the subordinates and others suffer (Mayer, Aquino, Greenbaum, \& Kuenzi, 2012). On the other hand, a growing number of conscious entrepreneurs, managers, and researchers believe 
that one of the root causes of global economic recession is the general managerial tendency to mismanage, misbehave, and misuse the human and other resources (Schawrtz, 2013). That is why ranking authorities consider ESG (environmental, social, and governance) issues to evaluate corporate behavior and to determine the future financial performance of companies together with non-financial performance indicators (Rubin, Dierdorff \& Brown, 2010).Moreover, ethical leadership together with external organizational stakeholders'pressure contribute to the social performance of the company in terms of environmentally sensitive and/or social responsible projects (Bekiroğlu, Erdil, \& Alpkan, 2011; Tian, Liu, \& Fan, 2015). Thus, leaders' ethical and responsible behaviors are encouraged and demanded.

From a normative and philosophical perspective, questions of "what should be?" and "what should be done?" are focused on, but the questions of "what is going on?" and "what does the current situation tell us?" remain underdeveloped and fragmented. Consequently, we focused on an expansive review of the relevant literature that have linked ethics and leadership. Accordingly, the question of how to improve ethical sensitivity in decision-making has begun to attract great attention (Schaubroeck et al., 2012). Thus, professionals have tried to consider developing ethical leadership in their organizations substantially, while scholars have begun to study its possible antecedents and outcomes. Emphasizing practical implications of ethical leadership, this study aims to analyze leaders' behaviors based on their ethical decisions, their adoption level of ethical leadership, the degree that they have integrated ethics into their management styles, and their relations with the followers and subordinates. In this respect, we investigated ethical leadership studies in top organizational behavior journals and categorized these studies according to their implications. The practical implications of these studies, which are related to ethical leadership in professional life, are examined in detail to excerpt a common idea about this specific style of leadership and its consequences in various industries.

\section{The Literature Review}

\section{Ethical Leadership - Definition, Relations and the Theoretical Origins}

It is so difficult to define ethics since almost everybody has his/her own explanation of ethics. In addition to difficulties in defining ethics, scholars, philosophers and thinkers are required to go back to ancient ages to capture the basic assumptions under ethics. In its simplest form, ethical behavior is intending to do the right thing. An important aspect of ethics also concerns the impact of a person's actions on others (Zhu, May, \& Avolio, 2004).However, the question of "what is right?" complicates things for long. From the extant literature that studied for the conceptualization and development of ethical leadership (Brown, Treviño, \& Harrison, 2005; Trevino et al., 2003; Treviño, Hartman, \& Brown, 2000), it is defined as the manifestation of normatively appropriate conduct through personal actions and interpersonal relationships, and the advancement of such conduct to followers through two-way communication reinforcement and decision-making.

Since the beginning of the $21^{\text {st }}$ century, leadership as a field has received a growing amount of attention through ethics, honesty, integrity, and truthfulness concepts. Ethical leaders' efforts to comprehend the world around them involve their capacities for inquiry, judgment, and action (Johnson, 2005). Pursuing ethics solely in any leader's actions is not sufficient to be perceived as an ethical leader. Thus, Johnson (2005) proposed four components of ethical leadership, 
namely purpose, knowledge, authority, and trust. In terms of purpose, an ethical leader is expected to make inquiries, legitimize, and act with organizational purposes in order to provide focus and consistency for decisions and accomplishments. The knowledge component of ethical leadership requires the knowledge to inquire, judge, and act carefully. This knowledge is found throughout the organization and its environment, but must be shared by those who hold it for the organization. The third component, authority refers to the power of an ethical leader to ask questions, make decisions, and act accordingly. The final component, trust, is the most important one that acts as a glue to connect all other components. The ethical leader inspires trust throughout the organization and its environment. Without trust people are afraid to exercise their authority, they can easily lose their purpose, and there is no need to use relevant knowledge.

Although ethics has also been an inseparable part of transformational and authentic leadership dimensions, ethical leadership has its place in leadership studies with a set of defined behaviors that form a separate leadership style in itself (Arda, Aslan, \& Alpkan, 2016; Brown et al., 2005; De Hoogh \& Den Hartog, 2008; Den Hartog \& De Hoogh, 2009; Kalshoven, Den Hartog, \& Den Hoog, 2011; Kanungo, 2001). Most attention to an ethical dimension of leadership has been embedded within the charismatic or transformational leadership while honesty and fair treatment paradigms were modeled as constructs of ethical leadership (Brown et al., 2005). Brown et al. (2005) identified three constructs that are related to ethical leadership. First construct is transformational/charismatic leadership since ethical leaders tend to use both transformational and transactional leadership approaches to followers' behavior. In their work, Brown et al. (2005) asserted that an ethical leader, who can influence employee outcomes, must be perceived as a credible and legitimate role model to make the ethics message more noticeable. Second, leader honesty as a construct in ethical leadership has a considerable effect showing that ethical leadership appears out of a mixture of characteristics and behaviors that involve revealing integrity and high ethical standards, considerate and fair treatment of employees, and holding employees accountable for ethical conduct. Third, considerate or fair treatment is another dimension that is considered as a part of ethics-related communication and reinforcement contribute to the salience of the leader's ethics message. In sum, leaders' role evolves around the practice of supporting the potential of all stakeholders by liberating their creativity, judgment abilities, and cooperative action to reach organizational goals (Johnson, 2005).

The extant literature on leadership studies have long relied on the relationship between leadership styles and outcomes in terms of individual and organizational standpoints. As the literature on ethical leadership continues to expand, the concept is linked with some basic notions that would be important to perceptions of leadership. As the studies related to ethical leadership has been developing, the evidence gathered from research suggests that ethical leadership has positive effects on both individuals and organizational effectiveness (Brown et al., 2005; Detert, Treviño, \& Sweitzer, 2008; Rubin et al., 2010). Ethical leadership and such related topics are studiedwith cultural reflections (Resick, Hanges, Dickson, \& Mitchelson, 2006; Resick, 2011; Toor \& Ofori, 2009; Martin, Resick, Keating, \& Dickson, 2009; Schwartz, 2013), leader-member exchange relations (Hassan, Mahsud, Yukl, \& Prussia, 2013; Mahsud, Yukl, \& Prussia, 2010), employee commitment and effectiveness (Bello, 2012; Zhu et al., 
2004; Walumbwa et al., 2011; Walumbwa, Morrison, \& Christensen, 2012; Walumbwa \& Schauubroeck, 2009), personality traits (Walumbwa \&Schaubroeck, 2009), core job characteristics (Piccolo, Greenbaum, Hartog, \& Folger, 2010), and employee stress and turnover intention (Elçi, Şener, Aksoy, \& Alpkan, 2012). Along with these positive associations of ethical leadership, there are also studies that investigate the relationship between ethical leadership and autocratic leadership (Nunnally \& Bernstein, 1994), lack of making decisions (Einarsen, Aasland, \& Skogstad, 2007; Yukl, 2010), passive leadership (Den Hartog, Van Muijen, \& Koopman, 1997). All these eminent studies give some important insights to both scholars and practitioners about the types of ethical leader behavior conducted by managers.

Theoretical foundations of ethical leadership suggest that ethical cultures are built on normative structures, which encourage individuals to engage in ethical behavior (Rubin et al., 2010). Social learning theory (Bandura, 1977, 1986) has been considered the base theory for ethical leadership studies in which ethical leaders perceived as role models for proper behaviors (Brown et al., 2005). Therefore, from the social learning perspective, by being a role model in behavior, an ethical leader will eventually inspire followers to behave in similar veins through imitation and observational leaning (Bandura, 1986; Brown et al., 2005; Kalshoven et al., 2011). Other than social learning approach, social exchange approach has also been used as theoretical basis for ethical leadership in some studies (Mayer,Kuenzi, Greenbaum, Bardes, \& Salvador, 2009; Turner, Barling, Epitropaki, Butcher, \& Midler, 2002). Researchers using a social exchange approach focus more on the norm for reciprocity (Cropanzano \& Mitchell, 2005) and asserted that followers are willing to reciprocate when treated fairly and with concern by their leaders (Mayer et al., 2009). Both views help scholars to understand individuals' reactions to ethical leader behavior. Other theories used in ethical leadership research by focusing on creating an ethical climate (Resick et al., 2006), using of power (Den Hartog \& De Hoogh, 2009), and path-goal theory (House, 1996). Describing ethical leadership in terms of path goal theory suggests that ethical leaders help followers on achieving personal goals, which should be in line with organizational goals, while sustaining high ethical standards (House, 1996; Kalshoven et al., 2011). Thus far, results on the effects of ethical leadership are positive; therefore, it may well be useful for organizations to invest in the development of ethical behavior.

\section{Method}

The research studies that exist in both ethics and leadership topics are considered. First, with this expansive category we conducted a literature review, which systemically conceptualizes and develops ethical leadership as a construct. Second, in order to identify the studies with practical implications for ethical leadership, we explore the extant literature to reach some relevant and useful implications for practice. First, ethical leadership studies in five highranking organizational behavior journals from 2010 to 2014as well as some important papers regarding ethical leadership and its implications are reviewed. Second, categorizations from the ones that have practical implications are selected for further examination. The papers are categorized according to their subjects and the practical implications are analyzed to excerpt a common idea. Regarding the review of the empirical studies and literature reviews devoted to 
ethical leadership and its various links, an online search of the ABI Inform, Emerald, and Science Direct databases was conducted. Organizational Behavior and Human Decision Processes, Organization Studies, Journal of Organizational Behavior, Journal of Behavioral Decision Making, and Leadership Quarterly were among the journals included into the study. Theoretical papers and those based on anecdotal evidence or case studies were also included in the study.

\section{Practical Implications Related with Ethical Leadership}

Amongst the studies that we take into account, some behavioral and attitudinal aspects of ethical leaders that are substantial in aligning and reorganizing their relationship with the followers are denoted. First, ethical leadership is driven by the culture and climate of the organization, which is formed by the senior management and maintained by mid-level managers. Leaders at all levels in an organization can help to create and maintain strong ethical culture by modeling and encouraging ethical behavior, challenging unethical actions and decisions, and holding everyone responsible for ethical conduct (Brown \&Treviño, 2006; Mahsud et al., 2010; Mayer et al., 2009; Yukl, 2010). Brown et al.(2005) emphasized that employees whose supervisor is perceived to be an ethical leader are more willing to engage in proactive helpful behavior such as reporting problems to management. Inspiring the development of behavioral norms of around ethics, organizational leaders could encourage voice within workgroups in order to support workgroup voice climate (Morrisson et al, 2011; Walumbwa et al., 2011; Walumbwa, Wheeler-Smith, \& Kamdar, 2011).

Second, one of the most important roles associated with ethical leaders is creating a positive work environment. Such environments are effective in attracting the best and the brightest employees and enabling long-lasting relations with almost all stakeholders(Carlson \& Perrewe, 1995).Through the positive role modeling and sending out strong messages about ethical conduct, leaders can develop a positive organizational culture and hence ethical context/climate that can facilitate the development of ethical and authentic leaders and followers (Toor \& Ofori, 2009; Gardner et al., 2005). An ethical climate obliges a sense making function for employees; to this end, they know how to answer to ethical issues (Mayer, Kuenzi, \& Greenbaum, 2010). It is also critical for human resource (HR) practices, policies, and procedures to emphasize the value of feeling as a fairly treated employee. For instance, performance evaluation procedures and results interpreted as unfair may destroy the psychological contract between the firm and its human capital. In order not to let this valuable resource be lost, establishment of a participative and ethical working climate is very instrumental (Birecikli, Alpkan, Ertürk, \& Aksoy, 2016).

There is an important difference between senior management and mid-level management in creating a positive climate. The former one is responsible for creating such climate and the latter is responsible for maintaining it. Organizational leaders are responsible for ethical culture, which represent the standards and boundaries for ethical conduct in their organizations. These shared elements can be traced by communicating with employees to determine whether leaders create unit ethical cultures that support ethical behavior or whether they create obstacles to it that might reduce followers' moral agency and increase the frequency and severity of unethical conduct (Schaubroeck et al., 2012). The lack of support from high-level 
management makes almost impossible to maintain an ethical climate. Moreover, when there is no convenient climate and a formed culture for an ethical leader to perform, misperceptions and misunderstandings among followers may be increased which in turn lead to decrease in employee commitment and trust. Thus, the key role belongs to upper management, which, in turn, creates the culture bounded with ethics, trust, and eventually commitment. The culture that supports ethics is in need of defining dimensions of ethical leadership in detail. One form of defining and sustaining ethical leadership conducts in an organization may be possible by creating an environment of organizational development and training. Moreover, management development programs and executive coaching can be used to improve interpersonal skills such as empathy (Mahsud et. al, 2010).

Third, ethical leadership has been examined a set of behaviors or a separate leadership style in itself ratherthan concentrating only on the ethical constituents of other leadership styles (Brown et al., 2005; De Hoogh \& Den Hartog, 2008; Den Hartog \& De Hoogh, 2009; Kalshoven et al., 2011; Kanungo, 2001). Moreover, it is important to note that recently, most of the CEOs, leaders, and managers have begun to be assessed by not only financial indicators but also by non-financial indicators like governance, corporate citizenship, and environmental issues. Executives have become more aware of the ethical dimension of leadership salient in the social context. Treviño, Brown, and Hartman (2003) suggested that leaders must carry a socially salient ethics agenda such as sharing information publicly about important organizational decisions, along with information about the principles and decisionmaking process. Organizations could provide their managers with development and training opportunities with respect to key characteristics or behavioral dimensions of virtuous leadership, namely prudence, temperance, justice, and fortitude (Riggio, Zhu, Reina, \& Maroosis, 2010).

Lastly, it is important to note that when ethical leadership is evaluated and practiced in multi-cultural contexts, the dimensions and conducts are likely to change and transform accordingly for conformity purposes. Different beliefs regarding ethical leadership may also pose challenges to business leaders in the context of parent-subsidiary relations (Martin et al., 2009). For multinational firms to maintain standards of ethical conduct on a global scale, managers need to understand the culturally specific expectations for ethical behavior (Martin et al., 2009; Trevino, Weaver, \& Reynolds, 2006).Recognition of differing perspectives on ethical leadership is critical for developing systems of mentoring and development in context, rather than attempting to implement a one size fits all approach (Resick et al., 2011). Thus, some generally accepted golden rules of ethical leadership should be defined in order to neutralize the effects of culture.

\section{Discussion and Conclusion}

Economic downturn combined with unethical decisions of leaders both from public and private sectors resulted in various scandals in organizations. As a result, enhancing subordinate work motivation and organizational commitment became more and more challenging for managers (Rubin et al., 2010). Moreover, current and future workforce regards values such as trust and loyalty, socially responsible organizations and ethical leaders that maintain positive relationships with employees as an important part of their work environment. Organizations 
that provide such climate to their employees attract the best and the most qualified workforce as well as benefit from solid relations with their stakeholders(Hassan et al., 2013). That is why non-financial issues are as important as financial performance of corporations and ethical leaders are the ones that may facilitate these non-financial issues within the organizations, which lead to an increase in overall performance.

It is vital to mention that honesty begins with being honest to ourselves. Human beings tend to be self-deceptive by relying on stereotypes rather than the facts so that they face with the risks and disadvantages of biased, unfair, and incorrect decisions. The key may be the acceptance of the fact that human beings have a great potential to trick themselves so that we can be, at least, aware of these irrational decisions to make them correct (Messick \& Bazerman, 2001). Whenever possible, executives should base their decisions on facts and data rather than hunches and assumptions (Messick \& Bazerman, 2001). There is an ongoing cliché that executives have been constantly facing with trade-offs between ethics and profits. However, Messick and Bazerman (1996) argued the opposite by asserting that unethical decision-making in all kinds of organizations is generally the consequences of psychological tendencies that lead to damaging and dysfunctional behaviors from both ethical and rational perspectives. The world around us is unpredictable and uncertain. However, in order to cope with the fear of uncertainty, human beings tend to accept that the world around us is certain and deterministic (Messick \& Bazerman, 1996). Acceptance of uncertainty, the biased nature of humans, and our ego-driven world might be a good start for being more ethical in all means.

\section{References}

Arda, Ö. A., Aslan, T., \& Alpkan, L. (2016). Review of practical implications in authentic leadership studies. Procedia-Social \& Behavioral Sciences, 229, 246-252.

Bandura, A. (1977). Social learning theory. Englewood Cliffs, NJ: Prentice-Hall.

Bandura, A. (1986). Social foundation of thought and action: A social cognitive theory. Englewood Cliffs, New Jersey: Prentice-Hall.

Bello, S. M. (2012). Impact of ethical leadership on employee job performance. International Journal of Business \& Social Science, 3(11), 228-238.

Bekiroğlu, C.., Erdil, O., \& Alpkan, L. (2011). Variables perceived by managers as antecedents that lead firms to environmental management: An empirical research in the turkish construction sector. Journal of Global Strategic Management, 5(1), 157174.

Birecikli, B., Alpkan, L., Ertürk, A., Aksoy, S. (2016). Employees' need for independence, organizational commitment, and turnover intentions: The moderating role of justice perceptions about performance appraisals. International Journal of Organizational Leadership, 5(3), 270-284.

Brown, M. E., Treviño, L. K., \& Harrison, D. A. (2005). Ethical leadership: A social learning perspective for construct development and testing. Organizational Behavior \& Human Decision Processes, 97(2), 117-134.

Brown, M. E., \& Treviño, L. K. (2006). Ethical leadership: A review and future directions. The Leadership Quarterly, 17(6), 595-616.

Carlson, D. S., \& Perrewe, P. L. (1995). Institutionalization of organizational ethics through transformational leadership. Journal of Business Ethics, 14(10), 829-838.

Cropanzano, R., \& Mitchell, M. S. (2005). Social exchange theory: An interdisciplinary review. Journal of Management, 31, $874-900$.

De Hoogh, A. H. B., \& Den Hartog, D. N. (2008). Ethical and despotic leadership, relationships with leader's social responsibility, top management team effectiveness and subordinates' optimism: A multi-method study. Leadership Quarterly, 19(3), 297-311. 
Den Hartog, D. N., \& De Hoogh, A. H. B. (2009). Ethical leadership: The positive and responsible use of power. In D. Tjsovold, \& B. Van Knippenberg (Eds.), Power and interdependence in organizations (pp. 338-358). Cambridge, UK: Cambridge University Press.

Den Hartog, D. N., Van Muijen, J. J., \& Koopman, P. L. (1997). Transactional versus transformational leadership: An analysis of the MLQ. Journal of Occupational \& Organizational Psychology, 70, 19-34.

Detert, J. R., Treviño, L. K., \& Sweitzer, V. L. 2008. Moral disengagement in ethical decision making: A study ofantecedents and outcomes. The Journal of Applied Psychology, 93, 374-391.

Einarsen, S., Aasland, M. S., \& Skogstad, A. (2007). Destructive leadership behavior: A definition and conceptual model. Leadership Quarterly, 18, 207-216.

Elçi, M., Şener, İ., Aksoy, S., \& Alpkan, L. (2012). The impact of ethical leadership and leadership effectiveness on employees' turnover intention: The mediating role of work related stress. Procedia Social \&Behavioral Sciences, 58, 289-297.

Gardner, W. L., Avolio, B. J., Luthans, F., May, D. R., \& Walumbwa, F. O. (2005). "Can you see the real me?” A self-based model of authentic leader and follower development. The Leadership Quarterly, 16(3), 343-372.

Hassan, S., Mahsud, R., Yukl, G., \& Prussia, G. E. (2013). Ethical and empowering leadership and leader effectiveness. Journal of Managerial Psychology, 28(2), 133-146.

House, R. J. (1996). Path-goal theory of leadership: Lessons, legacy and a reformulated theory. Leadership Quarterly, 7(3), $323-352$.

Johnson, K. W. (2005). The role of leadership in organizational integrity and five modes of ethical leadership. Ethical Leadership, EPIC-Online.net, 1-9.

Kacmar, K. M., Bachrach, D. G., Harris, K. J., \& Zivnuska, S. (2011). Fostering good citizenship through ethical leadership: Exploring the moderating role of gender and organizational politics. Journal of Applied Psychology, 96(3), 633-642.

Kalshoven, K., Den Hartog, D. N., \& De Hoogh, A. H. (2011). Ethical leadership at work questionnaire (ELW): Development and validation of a multidimensional measure. The Leadership Quarterly, 22(1), 51-69.

Kanungo, R. N. (2001). Ethical values of transactional and transformational leaders. Canadian Journal of Administrative Sciences, 18(4), 257-265.

Mahsud, R., Yukl, G., \& Prussia, G. (2010). Leader empathy, ethical leadership, and relations-oriented behaviors as antecedents of leader-member exchange quality. Journal of Managerial Psychology, 25(6), 561-577.

Martin, G. S., Resick, C. J., Keating, M. A., \& Dickson, M. W. (2009). Ethical leadership across cultures: A comparative analysis of German and US perspectives. Business Ethics: A European Review, 18(2), 127-144.

Mayer, D. M., Kuenzi, M., Greenbaum, R., Bardes, M., \& Salvador, R. B. (2009). How low does ethical leadership flow? Test of a trickle-down model. Organizational Behavior and Human Decision Processes, 108(1), 1-13.

Mayer, D. M., Kuenzi, M., \& Greenbaum, R. L. (2010). Examining the link between ethical leadership and employee misconduct: The mediating role of ethical climate. Journal of Business Ethics, 95, 7-16.

Mayer, D. M., Aquino, K., Greenbaum, R. L., \& Kuenzi, M. (2012). Who displays ethical leadership, and why does it matter? An examination of antecedents and consequences of ethical leadership. Academy of Management Journal, 55(1), 151-171.

Messick, D. M., \& Bazerman, M. H. (2001). Ethical leadership and the psychology of decision-making. In The next phase of business ethics: Integrating psychology and ethics (pp. 213-238). Emerald Group Publishing Limited.

Morrison, E. W., Wheeler-Smith, S. L., \& Kamdar, D. (2011). Speaking up in groups: A cross-level study of group voice climate and voice. Journal of Applied Psychology, 96(1), 183-191.

Nunnally, J. C., \& Bernstein, I. H. (1994). Psychometric Theory ( ${ }^{\text {rd }}$ ed.). New York: McGraw-Hill.

Ogunfowora, B. (2014). The impact of ethical leadership within the recruitment context: The roles of organizational reputation, applicant personality, and value congruence. The Leadership Quarterly, 25(3), 528-543.

Piccolo, R. F., Greenbaum, R., Hartog, D. N. D., \& Folger, R. (2010). The relationship between ethical leadership and core job characteristics. Journal of Organizational Behavior, 31(2/3), 259-278.

Resick, C. J., Hanges, P. J., Dickson, M. W., \& Mitchelson, J. K. (2006). A cross-cultural examination of the endorsement of ethical leadership. Journal of Business Ethics, 63(4), 345-359.

Resick, C. J., Martin, G. S., Keating, M. A., Dickson, M. W., Kwan, H. K., \& Peng, C. (2011). What ethical leadership means to me: Asian, American, and European perspectives. Journal of Business Ethics, 101(3), 435-457.

Riggio, R. E., Zhu, W., Reina, C., \& Maroosis, J. A. (2010). Virtue-based measurement of ethical leadership: The leadership virtues questionnaire. Consulting Psychology Journal: Practice \& Research, 62(4), 235-250. 
Rubin, R. S., Dierdorff, E. C., \& Brown, M. E. (2010). Do ethical leaders get ahead? Exploring ethical leadership and promotability. Business Ethics Quarterly, 20(02), 215-236.

Schaubroeck, J. M., Hannah, S. T., Avolio, B. J., Kozlowski, S. W., Lord, R. G., Treviño, L. K., \& Peng, A. C. (2012). Embedding ethical leadership within and across organization levels. Academy of Management Journal, 55(5), 1053-1078.

Schwartz, M. S. (2013). Developing and sustaining an ethical corporate culture: The core elements. Business Horizons, 56(1), $39-50$.

Tian, Q., Liu, Y., \& Fan, J. (2015). The effects of external stakeholder pressure and ethical leadership on corporate social responsibility in China. Journal of Management \& Organization, 21(4), 388-410.

Toor, S. U. R., \& Ofori, G. (2009). Ethical leadership: Examining the relationships with full range leadership model, employee outcomes, and organizational culture. Journal of Business Ethics, 90(4), 533-547.

Treviño, L. K., Hartman, L. P., \& Brown, M. (2000). Moral person and moral manager: How executives develop a reputation for ethical leadership. California Management Review, 42(4), 128-142.

Treviño, L. K., Brown, M., \& Hartman, L. P. (2003). A qualitative investigation of perceived executive ethical leadership: Perceptions from inside and outside the executive suite. Human Relations, 56(1), 5-37.

Treviño, L. K., Weaver, G. R., \& Reynolds, S. J. (2006). Behavioral ethics in organizations: A review. Journal of Management, 32(6), 951-990.

Turner, N., Barling, J., Epitropaki, O., Butcher, V., \& Milder, C. (2002). Transformational leadership and moral reasoning. The Journal of Applied Psychology, 87, 304-311.

Walumbwa, F. O., Morrison, E. W., \& Christensen, A. L. (2012). Ethical leadership and group in-role performance: The mediating roles of group conscientiousness and group voice. The Leadership Quarterly, 23(5), 953-964.

Walumbwa, F. O., Mayer, D. M., Wang, P., Wang, H., Workman, K., \& Christensen, A. L. (2011). Linking ethical leadership to employee performance: The roles of leader-member exchange, self-efficacy, and organizational identification. Organizational Behavior and Human Decision Processes, 115(2), 204-213.

Walumbwa, F. O., \& Schaubroeck, J. (2009). Leader personality traits and employee voice behavior: mediating roles of ethical leadership and work group psychological safety. Journal of Applied Psychology, 94(5), 1275-1286.

Zhang, X., Walumbwa, F. O., Aryee, S., \& Chen, Z. X. G. (2013). Ethical leadership, employee citizenship and work withdrawal behaviors: Examining mediating and moderating processes. The Leadership Quarterly, 24(1), 284-297.

Zhu, W., May, D. R., \& Avolio, B. J. (2004). The impact of ethical leadership behavior on employee outcomes: The roles of psychological empowerment and authenticity. Journal of Leadership \& Organizational Studies, 11(1), 16-26. 